Voix et Images

voixetimages

\title{
Le Spectacle de la littérature
}

\section{Benoît Melançon}

Volume 10, numéro 2, hiver 1985

La barre du jour / La nouvelle barre du jour

URI : https://id.erudit.org/iderudit/200505ar

DOI : https://doi.org/10.7202/200505ar

Aller au sommaire du numéro

Éditeur(s)

Université du Québec à Montréal

ISSN

0318-9201 (imprimé)

1705-933X (numérique)

Découvrir la revue

Citer cet article

Melançon, B. (1985). Le Spectacle de la littérature. Voix et Images, 10(2),

205-206. https://doi.org/10.7202/200505ar

Ce document est protégé par la loi sur le droit d'auteur. L'utilisation des services d'Érudit (y compris la reproduction) est assujettie à sa politique d'utilisation que vous pouvez consulter en ligne.

https://apropos.erudit.org/fr/usagers/politique-dutilisation/
Cet article est diffusé et préservé par Érudit.

Érudit est un consortium interuniversitaire sans but lucratif composé de l’Université de Montréal, l'Université Laval et l'Université du Québec à Montréal. Il a pour mission la promotion et la valorisation de la recherche. https://www.erudit.org/fr/ 


\title{
Le Spectacle de la littérature
}

\author{
par Benoit Melançon, Université de Montréal
}

Rendant compte de l'étude d'Hélène Lafrance sur Yves Thériault et l'Institution littéraire québécoise (voir Voix et Images, vol. X, no 1, pp. 174-175), nous soulignions l'importance croissante des analyses institutionnelles de la littérature québécoise et l'intérêt qu'y portent plusieurs chercheurs de l'Université de Sherbrooke. Le Spectacle de la littératurel est une nouvelle manifestation de ce phénomène. Sous un soustitre révélateur («Les aléas et les avatars de l'institution»), sont rassemblées des études sur «Le statut social de l'écrivain» (Giroux), «La voix des femmes pendant la Révolution tranquille; l'émergence des romancières» (Gauvreau), «Les fluctuations du capital symbolique; de l'outil et de l'institution» (Marquis), «L'écrivain, le scripteur et l'écriture» (Lemelin), «Lire ou thésauriser; la politique d'accumulation d'Un homme et son péché (Garand) et «Le champ littéraire au Québec» (Lemelin). Ces textes sont lâchement regroupés en deux parties: «L'écri-vain», "L'archi-texte». L'intérèt documentaire est là; pas toujours l'intérêt critique.

"On a l'impression à la lecture de ces textes que le recueil a été préparé hâtivement: Matériellement, l'ouvrage est peu soigné. Des notes rédigées à la va-vite (sur la polémique Herbes rouges / Nouvelle Barre du jour et sur un numéro récent d'Études françaises) côtoient des études de fond. Comme si la jeunesse de l'approche institutionnelle en faisait une forteresse à conquérir de toute urgence, les critiques se précipitent sur elle pour l'investir, se l'approprier, la charger d'un mythique pouvoir régénérateur: ainsi, le travail de Garand serait une «réflexion d'ensemble sur le problème de la lecture pour l'histoire et la théorie» - rien de moins. Le phénomène est, d'un point de vue institutionnel, fort intéressant: un nouveau créneau critique venant de s'ouvrir, s'y engouffrent des chercheurs (jeunes professeurs, étudiants) peu ou pas dotés au plan du capital symbolique attaché à la critique. Mais la compétition est féroce: il faut faire vite. C'est la littérature en spectacle.

Le projet, vaste, est celui de toutes les révolutions modernes, esthétiques comme critiques: "contribuer à la transformation de la littérature et des études littéraires», "sortir du mythe romantique de l'ecrivain".: Cette transformation, de nature eschatologique, doit d'abord être celle de la méthode: l'analyse institutionnelle à la Dubois et à la Bourdieu, avec un zeste de Jauss et de Girard (apport stimulant). Ensuite, de l'objet: les classiques (Grignon), mais aussi les oubliés, genres (1'essai) et auteurs (Eugène Dick, Jacqueline Francoeur, etc.). Enfin (surtout?), de ton: parenthèses, déconstructions sémantiques, chiasmes, humour appuyé, jeux sur l'étymologie, l'homophonie et la synonymie, etc. Pour conquérir le pouvoir symbolique, le critique doit également en déplacer le lieu: «A-t-on 
assez remarqué comment la critique, surtout la critique universitaire, trahit le texte d'autant plus qu'elle s'y prétend fidèle?». Cette rhétorique du cilice ne saurait mentir: l'enjeu est bien ici la domination esthétique ${ }^{2}$.

Au plan théorique, le problème est toujours celui des assises textuelles de l'approche institutionnelle: que peut une analyse inspirée de la sociologie face aux entités signifiantes que sont les textes? Certes, Lemelin affirme que «le textè est nécessairement institutionnel et l'institution est nécessairement textuellen; il faut lire les analyses ponctuelles publiées ici pour voir que le passage est difficile de ce parti pris théorique, si juste soit-il, à l'analyse concrète. La littérature est un spectacle, convenons-en, mais rappelons qu'il ne saurait être muet. On décrit bien une scène, des acteurs, des publicistes, beaucoup d'admirateurs, quelques zélotes; tout, pourtant, reste jeux de coulisses. On ne dit rien: pas de texte. Une critique nourrie d'elle-même.

Ce silence sur les textes et la complaisance de l'écriture chez Giroux et Lemelin ne devraient pas faire oublier les mérites de l'ouvrage. Celui, d'abord, d'élargir le champ couvert par l'analyse institutionnelle au Québec. Celui, également, d'approfondir quelques-uns des concepts-clés de Bourdieu et du Dubois: la relativité de l'institution, à laquelle on préfère la notion de "spécificité», l'importance attachée à l'acte de lecture, le caractère religieux du fonctionnement institutionnel, l'institution en tant que "grammaire», en plus de divers éléments de nature documentaire (lecture de journaux, études de réception, statistiques). Le mérite, enfin, de lancer la discussion, voire la polémique. On peut toutefois se demander si c'est bien la le projet des auteurs. En effet, on pourrait retourner l'épigraphe, tirée d'Uni homme et son péché,-du texte de Garand, pour l'appliquer à l'ensemble de l'entreprise:

"Comme les genoux du cadavre dépassaient un peu la bière, Séraphin pesa dessus et un craquement d'os se fit entendre.

- Il va faire correct, conclut-il.

Et il vissa lui-même le cercueil.»

1 Sous la direction de Robert Giroux et Jean-Marc Lemelin, le Spectacle de la littérautre. Les aléas et les avatars de l'institution, Montréal, Editions Triptyque, 1984, 251 p. Textes de Dominique Garand, Liette Gaudreau, Robert Giroux, Jean-Marc Lemelin et André Marquis.

2. Témoigne également de cette quete la position d'outsider que voudrait bien se créer JeanMarc Lemelin autant dáns ses textes, par des positions théoriques posées comme fondatrices, que dans sa propre bibliographie, voir la page consacrée d ses travaux ua diffusion limitée" (mémoire de man̂trise, etc.). On lira dans le même sens le jeu de publicité mutuelle pratiqué ici, d'un article à l'autre, d'un critique à l'autre. 